\title{
Metabolic, inflammatory and haemostatic effects of a low- dose continuous combined HRT in women with type 2 diabetes: potentially safer with respect to vascular risk?
}

Joyce McKenzie ${ }^{\star}$, Alan J. Jaapף, Stephen Gallacher ${ }^{\star *}$, Anne Kellyt, Lynne Crawford†, lan A. Greerł, Ann Rumley§, John R. Petrie§, Gordon D. Lowe§, Kenneth Paterson* and Naveed Sattar†

${ }^{*}$ Diabetes Centre and Departments of $†$ Pathological Biochemistry, $¥$ Obstetrics and Gynaecology and $\S$ Medicine, Glasgow Royal Infirmary University NHS Trust, Glasgow, $\{$ Department of Medicine, Crosshouse Hospital, Kilmarnock, and ${ }^{* *}$ Department of Medicine, Southern General Hospital, Glasgow, UK

(Received 30 May 2003; returned for revision 17 July 2003; finally revised 18 July 2003; accepted 23 July 2003)

\section{Summary}

BACKGROUND Conventional hormone replacement therapy (HRT) containing conjugated equine oestrogen (CEE) and medroxyprogesterone acetate (MPA) increases triglyceride, C-reactive protein (CRP) and coagulation Factor VII concentrations, potentially explaining their increased coronary heart disease (CHD) and stroke risk.

OBJECTIVE To assess the metabolic effects of a continuous combined HRT containing $1 \mathrm{mg}$ oestradiol and $\mathbf{0 . 5} \mathrm{mg}$ norethisterone or matching placebo.

DESIGN Double-blind, randomized placebo-controlled trial.

PATIENTS Fifty women with type 2 diabetes.

MEASUREMENTS Classical and novel risk factors for vascular disease.

RESULTS Triglyceride concentration was not altered $(P=0.31$, change in active arm relative to placebo) and low-density lipoprotein (LDL) cholesterol concentration declined $13 \%(P=0.018)$. IL-6 concentration (mean difference $-1.42 \mathrm{pg} / \mathrm{ml}, 95 \% \mathrm{Cl}:-2.55$ to $-0.29 \mathrm{lU} / \mathrm{dl}$, $P=0.015)$, Factor VII ( $-32 \mathrm{IU} / \mathrm{dl},-43$ to $-21 \mathrm{IU} / \mathrm{I}, P<0.001$ ) and tissue plasminogen activator antigen (by $13 \%$, $P=0.005$ ) concentrations fell, but CRP was not signif-

Correspondence: Dr Naveed Sattar, University Department of Pathological Biochemistry, Glasgow Royal Infirmary, Glasgow G31 2ER, UK. Tel: +44 141211 4312; Fax: +44 141553 2558;

E-mail: nsattar@clinmed.gla.ac.uk icantly altered $(P=0.62)$. Fasting glucose $(P=0.026)$ also declined significantly, but there are no significant effects on HBA1c, Factor IX or APC resistance.

CONCLUSIONS HRT containing $1 \mathrm{mg}$ oestradiol and $0.5 \mathrm{mg}$ norethisterone may avoid the adverse metabolic effects potentially implicated in the elevated CHD and stroke risk induced by conventional higher dose HRT. This type of preparation may therefore be more suitable than conventional HRT for women at elevated CHD risk such as those with type 2 diabetes. Large randomized controlled trials of such low dose preparations, powered for cardiovascular end points, are now needed.

Until the publication of the Heart and Oestrogen/Progestogen Replacement Study (HERS; Hulley et al., 1998), and more recently of the Women's Health Initiative (WHI) study (Rossouw et al., 2002), many women and their physicians were convinced of the cardio-protective effects of hormone replacement therapy (HRT). In HERS, women with established CHD were randomized to $0.625 \mathrm{mg} /$ day conjugated equine oestrogen (CEE) plus $2.5 \mathrm{mg} /$ day medroxy-progesterone acetate (MPA) or matching placebo. The HRT group experienced an elevation in coronary heart disease (CHD) risk in the first year of use and no overall difference in events over 4 years (Hulley et al., 1998). The WHI used the same preparation in a primary prevention setting and also reported an increased risk of CHD and of stroke in the active arm compared to placebo (Rossouw et al., 2002), and more recently a potential deleterious effect on cognitive function (Rapp et al., 2003). Therefore, despite a beneficial effect of this preparation on low-density lipoprotein (LDL) and HDL cholesterol concentrations, other effects may be unfavourable; the search for these is receiving intense scrutiny. Most current attention has focussed on possible triglyceride-raising, pro-coagulant and pro-inflammatory effects of CEE and $2 \mathrm{mg}$ oestradiol containing HRTs (Kroon et al., 1994; Petitti, 1998; van Baal et al., 1999b; Cushman et al., 1999; Ridker et al., 1999; Lowe et al., 2001b) but data on preparations containing low dose oestradiol combined to norethisterone, particularly from randomised placebo-controlled trials, are sparse.

Women with type 2 diabetes have a markedly elevated baseline risk for CHD. A recent report from a prospective observational study (Lokkegaard et al., 2003) suggested that HRT use leads to 
a significantly increased risk of death from all causes and ischaemic heart disease among women with diabetes. Current users of HRT with diabetes had a near 10-fold increased risk of myocardial infarction $[9 \cdot 2,95 \%$ confidence interval (CI), 2.041.4] compared with never users with diabetes. By contrast, Ferrara et al. (2003) noted that among diabetic women who did not have a recent myocardial infarction, current HRT use was associated with a significant $16 \%$ lower risk of acute myocardial infarction. Thus HRT effects on CHD risk in diabetes are controversial and randomized trials are required.

HRT preparations are not homogeneous with respect to metabolic effects: metabolic actions are profoundly altered according to route of delivery, dose and chemical nature of the combined oestrogenic and progestogenic preparations (Knopp \& Zhu, 1997). Data from trials with differing designs suggest that lower doses of oestradiol (1 mg) or transdermal preparations may have fewer deleterious and (perhaps) even beneficial effects on inflammatory and haemostatic pathways (van Baal et al., 1999a; Sattar et al., 1999; Lowe et al. et al., 2001b; Perera et al., 2001; Vehkavaara et al., 2001). In addition, there is an increasing awareness that androgenic progestogens such as norethisterone may offer several advantages over MPA, particularly with respect to coagulation and inflammatory parameters (Sattar et al., 1999; Perera et al., 2001).

The aim of the present randomized double-blind placebocontrolled study therefore was to examine the metabolic effects of a novel continuous combined preparation containing $1 \mathrm{mg}$ oestradiol and $0.5 \mathrm{mg}$ norethisterone in women with type 2 diabetes. We comprehensively assessed key pathways, including lipids and glycaemic parameters, and haemostatic and inflammatory pathways, known to be influenced by hormonal regulation and relevant to CHD risk. The hypothesis was that this low-dose oestradiol preparation combined with norethisterone would continue to reduce LDL cholesterol, limit any triglyceride rise and would have fewer potentially adverse effects on key coagulation and inflammatory parameters than observed with conventional CEE/MPA-based preparations.

\section{Methods}

\section{Subjects}

From December 1998 to September 2000, 50 women with type 2 diabetes aged under 70 years of age were recruited from general diabetic clinics in Glasgow Hospitals. Women randomized were clinically and biochemically postmenopausal, i.e. at least 1 year since last menses and a FSH concentration of greater than $20 \mathrm{IU} /$ 1. Menopause could be either natural or surgically induced. A normal pelvic examination and mammogram within the year prior to inclusion in the trial was also required.

Exclusion criteria comprised: poor glycaemic control; severe hypertriglyceridaemia (>10 mmol/1); moderate to severe hyper-
Table 1 Baseline characteristics of study groups

\begin{tabular}{lcc}
\hline & \multicolumn{2}{l}{ Group } \\
\cline { 2 - 3 } & Active, $n=19$ & Placebo, $n=22$ \\
\hline Age (years) & $60 \cdot 7(5 \cdot 5)$ & $61 \cdot 3(4 \cdot 8)$ \\
BMI $\left(\mathrm{kg} / \mathrm{m}^{2}\right)$ & $30 \cdot 5(6 \cdot 5)$ & $29 \cdot 8(5 \cdot 61)$ \\
Waist circumference $(\mathrm{cm})$ & $93 \cdot 9(11 \cdot 3)$ & $93 \cdot 7(13 \cdot 6)$ \\
Years postmenopausal & $14 \cdot 6(8 \cdot 5)$ & $14 \cdot 2(6 \cdot 3)$ \\
Smokers (yes/no) & $6 / 19$ & $5 / 22$ \\
Systolic blood pressure $(\mathrm{mmHg})$ & $152(17)$ & $151(21)$ \\
Diastolic blood pressure $(\mathrm{mmHg})$ & $87(8)$ & $83(9)$ \\
Medications & & \\
Diet alone $(n)$ & 5 & 3 \\
Oral hypoglycaemics $(n)$ & 10 & 11 \\
Insulin $(n)$ & 4 & 9 \\
Anti-hypertensives $(n)$ & 10 & 10 \\
Lipid-lowering agents $(n)$ & 5 & 5 \\
\hline
\end{tabular}

Mean (SD) reported.

tension (systolic $>160 \mathrm{mmHg}$, diastolic $>110 \mathrm{mmHg}$ ); renal impairement (serum creatinine greater than twice the upper limit of normal range); liver disease (serum transaminases and bilirubin greater than twice the upper limit of normal range); or established cardiovascular, cerebrovascular, or peripheral vascular disease. Subjects with either a personal history of - or first-degree relative with - breast cancer were excluded.

Women eligible at screening were randomized to prescription of either active medication ( $1 \mathrm{mg}$ oestradiol plus $0.5 \mathrm{mg}$ norethisterone) or identical placebo daily for 6 months. Randomization was effected in blocks of four using computer-generated numbers. Compliance was assessed by returned medication packs at the final visit and by oestradiol and gonadotrophin concentration measures at the final visit. A requirement of oestradiol to rise by more than $10 \mathrm{pmol} / 1$ and FSH to decline by more than $5 \mathrm{U} / 1$ was predefined.

The participating hospitals' local research ethical committees granted approval. All subjects gave written informed consent to a single investigator (JM). As far as possible, existing medications for glycaemic control, blood pressure or lipid lowering (detailed in Table 1) were not altered throughout the course of the study.

We determined that our sample size had $80 \%$ power to detect a $5 \%$ reduction in LDL cholesterol and $90 \%$ power to detect a $5 \%$ reduction in factor VII with $\alpha=0 \cdot 05$.

\section{Study visits}

Women attended the Diabetes Centre, Glasgow Royal Infirmary, Glasgow at baseline and 6 months, having fasted for $10 \mathrm{~h}$ and avoided heavy exercise, alcohol and caffeine in the 


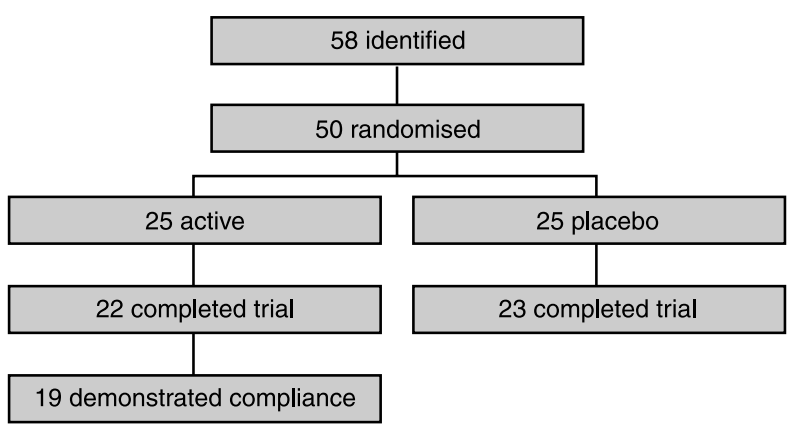

Fig. 1 Trial outcome flow chart.

preceding $24 \mathrm{~h}$. Subjects rested prone for 15 min prior to blood pressure recordings being taken in triplicate (mean recorded). The women also had anthropometric measurements to include height $(\mathrm{cm})$, weight $(\mathrm{kg})$ and waist and hip circumferences $(\mathrm{cm})$. From these, body mass index (BMI) was calculated as weight $/(\text { height })^{2}$ in $\mathrm{kg} / \mathrm{m}^{2}$, as well as waist to hip ratio (WHR).

\section{Laboratory methods}

The reproductive hormones: oestradiol, LH, FSH, testosterone and SHBG were measured using semiautomated 'Immulite' technology (DPC, Los Angeles, CA, USA). Plasma total cholesterol, triglyceride, LDL cholesterol and HDL cholesterol were determined by a modification of the standard Lipid Research Clinics Protocol. The intra-assay and interassay coefficients of variation $(\mathrm{CVs})$ for lipid measures were both less than 3\%. Fibrinogen, factor VII and factor IX, activated protein C (APC) ratio and tissue plasminogen activator (t-PA) antigen were measured in citrated plasma $(0 \cdot 11 \mathrm{~m}$ trisodium citrate; $9: 1, \mathrm{v}: \mathrm{v})$ as previously described (Woodward et al., 1997; Lowe et al., 1998, 2001a). The APC ratio measurement was an APTT-based test rather than a Factor $\mathrm{V}$ prediluted test. The intra-assay CVs for these haemostatic mediators were all less than 5\%. C-peptide was measured using the DPC Immulite 2000 analyser with a CV of $<7 \%$. Plasma glucose was measured using the glucose oxidase method (Glucose Reagent Kit - Olympus AU5200, Olympus Optical Co Ltd, Tokyo, Japan).

CRP concentration was measured using an in-house sensitive double antibody sandwich enzyme-linked immunosorbent assay (ELISA) as described previously (Sattar et al., 1999). The assay was linear up to $5 \mathrm{mg} / 1$ and logarithmic thereafter, and had a lower detection limit of $0.10 \mathrm{mg} / 1$. The inter- and intra-assay coefficients of variation were less than $10 \%$ across the range of measured results. Sensitive IL-6 was measured by double antibody sandwich ELISA (R \& D Systems, Minneapolis, MN, USA) with an intra-assay CV of $8 \%$.

\section{Statistical analysis}

Mean differences in changes from baseline between the two treatment groups were compared using the unpaired $t$-test: the $95 \%$ $\mathrm{CI}$ for change in active group data relative to change in control group data are presented. Adjustment for baseline concentrations was made by linear regression. Baseline data are presented as mean and SD or median and interquartile range (IQR) for parameters exhibiting skewed distribution.

\section{Results}

Fifty-eight women were screened as potential recruits into the study. Of these, 50 were randomized (Fig. 1). The eight women not entered had unacceptably high $\mathrm{HbAlc}(n=3)$, abnormal liver function tests $(n=2)$, abnormal mammogram $(n=2)$ or abnormal pelvic examination $(n=1)$. Five women did not complete the study due to either relocating or personal reasons. Thus, 45 women completed the study: of the 22 in the active group, 19 demonstrated adherence to study medications by predetermined criteria. Data from women falling outside these criteria were omitted from subsequent analyses. There were no serious adverse events. Breast tenderness and breakthrough bleeding were reported by three women on active treatment and by none on placebo.

Table 1 demonstrates the baseline characteristics of women completing the study. The two groups allocated to treatment were similar in age, BMI, blood pressure and years since menopause. All categories of diabetes therapy were represented and similar percentages were taking antihypertensive or lipid-lowering agents. The treatment groups also showed similar baseline hormonal and lipid concentrations (Tables 2 and 3).

A significant reduction in gonadotrophin concentrations and an elevation in oestradiol (all $P<0 \cdot 001$ ) and SHBG levels $(P=0.042)$ was observed in those women randomized to active therapy as a group (Table 2). Total testosterone was not altered significantly but free androgen index fell significantly $(P<0.001$, data not shown).

Table 3 demonstrates lipid and glycaemic changes in the groups. Both total (10\%) and LDL cholesterol (13\%) concentrations were reduced significantly with active treatment $(P<0.05)$ but HDL cholesterol and triglyceride were not altered. Similarly, fasting C-peptide was reduced by $19 \%(P<0.01 v s$. change in placebo). Fasting glucose was also reduced $(P<0.05)$ in the active arm as was HbAlc but the latter change did not reach significance $(P>0 \cdot 10)$.

Haemostatic and inflammatory variables are presented in Table 4. Significant reductions in Factor VII levels $(P<0 \cdot 001)$, and t-PA antigen and IL-6 concentrations $(P<0.02)$ were observed without significant alteration in factor IX, APC resistance (APC ratio), fibrinogen or CRP concentrations. 
Table 2 Sex hormone changes in active and placebo groups

\begin{tabular}{|c|c|c|c|c|c|c|}
\hline & \multicolumn{2}{|l|}{ Active } & \multicolumn{2}{|l|}{ Placebo } & \multirow[b]{2}{*}{$\begin{array}{l}\text { Difference for } \Delta \text { active relative } \\
\text { to } \Delta \text { placebo }(95 \% \mathrm{CI})\end{array}$} & \multirow[b]{2}{*}{$P$} \\
\hline & Baseline & $\begin{array}{l}\text { Mean } \\
\text { change }\end{array}$ & Baseline & $\begin{array}{l}\text { Mean } \\
\text { change }\end{array}$ & & \\
\hline LH (IU/1) & $35(26-39)$ & $-23 \cdot 7$ & $37(24-44)$ & $-0 \cdot 4$ & $-23(-32-(-15))$ & $<0.001$ \\
\hline FSH (IU/1) & $53(49-83)$ & $-41 \cdot 8$ & $60(48-81)$ & $-2 \cdot 5$ & $-39(-50-(-28))$ & $<0.001$ \\
\hline Oestradiol $(\mathrm{pmol} / \mathrm{l})$ & $63 \cdot 3(15 \cdot 9)$ & 165 & $65 \cdot 4(14 \cdot 6)$ & $2 \cdot 0$ & $163(111-215)$ & $<0.001$ \\
\hline Testosterone $(\mathrm{nmol} / \mathrm{l})$ & $1.23(0.63)$ & $-0 \cdot 12$ & $1 \cdot 19(0.33)$ & $0 \cdot 0$ & $-0 \cdot 12(-0 \cdot 42-0 \cdot 17)$ & $0 \cdot 410$ \\
\hline $\operatorname{SHBG}(\mathrm{nmol} / \mathrm{l})$ & $33(21-52)$ & $15 \cdot 7$ & $37(27-49)$ & $1 \cdot 4$ & $14 \cdot 3(0 \cdot 52-28 \cdot 1)$ & $0 \cdot 042$ \\
\hline
\end{tabular}

Baseline data are given as mean (SD) or median (interquartile range).

Table 3 Lipids and insulin/glycaemia changes in active and placebo groups

\begin{tabular}{|c|c|c|c|c|c|c|}
\hline & \multicolumn{2}{|l|}{ Active } & \multicolumn{2}{|l|}{ Placebo } & \multirow[b]{2}{*}{$\begin{array}{l}\text { Difference for } \Delta \text { active relative } \\
\text { to } \Delta \text { placebo }(95 \% \mathrm{CI})\end{array}$} & \multirow[b]{2}{*}{$P$} \\
\hline & Baseline & $\begin{array}{l}\text { Mean } \\
\text { change }\end{array}$ & Baseline & $\begin{array}{l}\text { Mean } \\
\text { change }\end{array}$ & & \\
\hline \multicolumn{7}{|l|}{ Lipids } \\
\hline Cholesterol (mmol/l) & $6.02(1.07)$ & $-0 \cdot 62$ & $5.68(0.97)$ & $-0 \cdot 13$ & $-0.49(-0.05-(-0.90))$ & $0 \cdot 020$ \\
\hline LDL-C $(\mathrm{mmol} / \mathrm{l})$ & $4 \cdot 14(0 \cdot 93)$ & $-0 \cdot 55$ & $3 \cdot 80(1.00)$ & $-0 \cdot 10$ & $-0.44(-0.79-(-0.08))$ & $0 \cdot 018$ \\
\hline HDL-C (mmol/1) & $1 \cdot 30(0 \cdot 32)$ & $-0 \cdot 07$ & $1 \cdot 36(0 \cdot 29)$ & $-0 \cdot 06$ & $0 \cdot 01(-0 \cdot 10-0 \cdot 10)$ & $0 \cdot 830$ \\
\hline Chol:HDL-C ratio & $4 \cdot 88(1.58)$ & $-0 \cdot 28$ & $4 \cdot 46(1.53)$ & $0 \cdot 20$ & $-0.48(-0.99-0.00)$ & $0 \cdot 050$ \\
\hline Triglyceride $(\mathrm{mmol} / \mathrm{l})$ & $1.75(1 \cdot 15-2 \cdot 35)$ & $-0 \cdot 034$ & $1 \cdot 68(1 \cdot 25-2 \cdot 21)$ & $0 \cdot 16$ & $-0 \cdot 19(-0 \cdot 58-0 \cdot 19)$ & $0 \cdot 310$ \\
\hline \multicolumn{7}{|l|}{ Glycaemia } \\
\hline C-peptide (nmol/1) & $0.97(0.65-1.29)$ & $-0 \cdot 18$ & $0 \cdot 79(0 \cdot 49-1 \cdot 51)$ & 0.09 & $-0 \cdot 27(-0.44-(-0.09))$ & $0 \cdot 003$ \\
\hline Glucose $(\mathrm{mmol} / 1)$ & $12 \cdot 4(4 \cdot 2)$ & $-1 \cdot 74$ & $11 \cdot 3(3 \cdot 2)$ & $0 \cdot 42$ & $-2 \cdot 16(-4 \cdot 06-(-0 \cdot 28))$ & $0 \cdot 026$ \\
\hline HBA1c $(\%)$ & $10 \cdot 2(1 \cdot 8)$ & $-0 \cdot 37$ & $10 \cdot 2(1 \cdot 3)$ & $0 \cdot 22$ & $-0.59(-1.45-0.27)$ & $0 \cdot 170$ \\
\hline
\end{tabular}

Baseline data are given as mean (SD) or median (interquartile range).

Table 4 Haemostatic and inflammatory changes in active and placebo groups

\begin{tabular}{|c|c|c|c|c|c|c|}
\hline & \multicolumn{2}{|l|}{ Active } & \multicolumn{2}{|l|}{ Placebo } & \multirow[b]{2}{*}{$\begin{array}{l}\text { Difference for } \Delta \text { active relative } \\
\text { to } \Delta \text { placebo }(95 \% \mathrm{CI})\end{array}$} & \multirow[b]{2}{*}{$P$} \\
\hline & Baseline & $\begin{array}{l}\text { Mean } \\
\text { change }\end{array}$ & Baseline & $\begin{array}{l}\text { Mean } \\
\text { change }\end{array}$ & & \\
\hline \multicolumn{7}{|l|}{ Haemostatic factors } \\
\hline Factor VII (IU/dl) & $160(36)$ & $-26 \cdot 7$ & $152(31)$ & $5 \cdot 50$ & $-32(-43-(-21))$ & $<0.001$ \\
\hline Factor IX (IU/dl) & $163(42)$ & $7 \cdot 00$ & $155(40)$ & $3 \cdot 60$ & $3 \cdot 7(-9 \cdot 9-16 \cdot 3)$ & $0 \cdot 490$ \\
\hline APC ratio & $2 \cdot 74(0 \cdot 6)$ & $0 \cdot 25$ & $2 \cdot 74(0 \cdot 5)$ & $0 \cdot 23$ & $0 \cdot 0(-0 \cdot 25-0 \cdot 25)$ & 0.990 \\
\hline tPA-antigen (ng/ml) & $14.9(5 \cdot 6)$ & $-2 \cdot 01$ & $12 \cdot 7(3 \cdot 8)$ & $0 \cdot 97$ & $-2 \cdot 98(-5 \cdot 00-(-0 \cdot 95))$ & $0 \cdot 005$ \\
\hline Fibrinogen $(\mathrm{g} / \mathrm{l})$ & $3 \cdot 91(0 \cdot 68)$ & $0 \cdot 02$ & $3.89(0.92)$ & $-0 \cdot 12$ & $0 \cdot 14(-0 \cdot 19-0 \cdot 47)$ & $0 \cdot 390$ \\
\hline \multicolumn{7}{|l|}{ Inflammatory factors } \\
\hline $\mathrm{CRP}(\mathrm{mg} / \mathrm{l})$ & $5 \cdot 05(4 \cdot 46-8 \cdot 53)$ & $1 \cdot 45$ & $3 \cdot 37(1 \cdot 76-8 \cdot 10)$ & $0 \cdot 72$ & $0 \cdot 73(-2 \cdot 27-3 \cdot 72)$ & 0.620 \\
\hline IL-6 (pg/ml) & $3 \cdot 46(2 \cdot 48-4 \cdot 89)$ & $-0 \cdot 32$ & $3 \cdot 55(2 \cdot 11-4 \cdot 47)$ & $1 \cdot 10$ & $-1 \cdot 42(-2 \cdot 55-(-0 \cdot 29))$ & $0 \cdot 015$ \\
\hline
\end{tabular}

Baseline data are given as mean (SD) or median (interquartile range).

Significance values were also checked with adjustment for baseline concentrations of all parameters measured. The results were in keeping with unadjusted values: specifically, reductions in cholesterol (adjusted $P=0 \cdot 032$ ), Factor VII (adjusted $P<0 \cdot 001$ ), tPA- antigen (adjusted $P=0 \cdot 01$ ) and IL-6 (adjusted $P=0 \cdot 045$ ) were similar and CRP remained similarly unchanged (adjusted $P=0 \cdot 96$ ).

Finally, we determined the number of patients randomized to HRT or placebo that achieved $10 \%$ decline in LDL cholesterol 
and Factor VII concentration using an intention to treat analysis. A $10 \%$ decline is either parameter in clinically relevant. Ten of the 25 in the HRT group had $>10 \%$ decline in LDL cholesterol compared to only four in the placebo group $(P=0.059$, Chisquare test). For Factor VII, 16 of the 25 in the HRT group had $>10 \%$ decline in Factor VII, whereas only one of the 25 in the placebo group did so $(P<0 \cdot 0001)$.

\section{Discussion}

Our study is one of the very few randomized double-blind placebo-controlled trials of HRT in diabetic women, albeit in an older group than those who would normally receive HRT. More importantly, it is the largest study to date to examine metabolic actions of a novel continuous combined preparation containing $1 \mathrm{mg}$ oral oestradiol and $0.5 \mathrm{mg}$ norethisterone in a high CHDrisk population. The key results were lowered plasma LDL cholesterol, Factor VII, t-PA antigen and IL-6 concentrations, and statistically similar triglyceride, Factor IX, APC resistance and CRP levels. This pattern of effects differs markedly from the profile produced by normal-dose HRT containing CEE and MPA used in HERS and WHI which increase triglyceride, Factor VII and promote a doubling in CRP concentrations (Hulley et al., 1998; Petitti, 1998). As a result, an HRT containing low-dose oestradiol and norethisterone may be more suitable for women who have an elevated risk of CHD (e.g. those with type 2 diabetes), who require HRT for menopausal symptom relief or bone protection. Formal clinical trials are required to test this suggestion.

The potentially better portfolio of metabolic effects of the HRT in this study may result either from the use of a low oestradiol dose or from the use of a more androgenic progestogen, norethisterone. More likely is that the balance of effects deriving from this HRT lean more towards androgenic rather than oestrogenic actions. This is an important point as conventional wisdom has dictated the use of nonandrogenic progestogens to minimize any HDL cholesterol reducing effect (Petitti, 1998). Clearly, this course of action needs re-evaluation as HDL cholesterol was unchanged in the present study.

With respect to the inflammation cascade, HRTs containing $2 \mathrm{mg}$ oestradiol or CEE elevate CRP concentrations almost twofold (Ridker et al., 1999; Lowe et al., 2001b). In the observational arm of the (large) WHI, current HRT use was associated with higher CRP but, interestingly, similar IL-6 levels in those women not taking HRT (Pradhan et al., 2002). Moreover, transdermal delivery of oestradiol appears not to be associated with elevation of CRP (Sattar et al., 1999; Lowe et al., 2001b; Vehkavaara et al., 2001) which therefore may represent a 'first pass' effect on hepatic CRP synthesis (Lowe et al., 2001b). Because elevated CRP levels in men and women are independently linked to risk for CHD and stroke (Ridker, 2001), the HRTinduced CRP rise has been put forward as a potential pathway explaining the results of HERS and WHI (Kroon et al., 1994; Ridker et al., 1999). It should be acknowledged, however, that even though vascular literature suggests several mechanisms whereby CRP may be directly atherogenic (Ridker, 2001), it is not yet known whether the HRT-induced CRP rise leads directly or indirectly to a biologically adverse outcome.

Our data demonstrate a lack of significant rise in CRP in those assigned active therapy compared to the placebo group $(P=0.62$ crude, $P=0.96$ adjusted difference). Although power may be an issue here, studies in similar size to the present one, but employing CEE- or $2 \mathrm{mg}$ oestradiol-based preparations, have demonstrated significant, near twofold elevations in CRP (van Baal et al., 1999b; Manning et al., 2002). A lack of CRP rise in the present study concurs with results from two other studies in nondiabetic women that used lower oestradiol doses (1 mg; van Baal et al., 1999a; Stork et al., 2002). Moreover, HRT combining oral norethisterone with transdermal oestradiol may lower CRP (Sattar et al., 1999); thus any tendency to an oestradiol-induced CRP elevation in the present study may have been attenuated by the oral norethisterone. The reduction in IL-6 concentration is of interest as androgens exhibit anti-inflammatory effects in several tissues (Gornstein et al., 1990). Because of the variability of circulating inflammatory markers and the wide confidence interval in the result reported in this and studies of similar size (van Baal et al., 1999a; Zanger et al., 2000), larger studies using low-dose HRT preparations are now urgently required to confirm our findings. In this respect, a potentially lower CHD risk with lower doses of HRT has recently been suggested by Ferrera et al. (2003) in their analysis of data from the Northern California Kaiser Permanente Diabetes Registry.

That triglyceride did not rise in this study is also relevant to CHD risk. Oral oestrogens, particularly CEE-based preparations, significantly increase circulating triglyceride concentrations by increasing hepatic synthesis of triglyceride-rich particles (Knopp et al., 1997). Increases in triglyceride concentration may enhance plaque instability by affecting platelet and endothelial function, as well as altering coagulation and vascular inflammation (Sattar et al., 1998; Dichtl et al., 1999). Triglyceride concentration is independently linked to CHD risk, particularly in women (Hokanson \& Austin, 1996). Indeed, the HERS investigators speculated that the $10 \%$ rise in triglyceride concentration in their study may have contributed to the early increase in CHD events despite the positive changes in other lipid parameters (Hulley et al., 1998). In general, increase in triglyceride concentration is less pronounced with oral oestradiol-containing HRTs compared to CEE-based HRTs and absent with transdermal delivery (Knopp et al., 1997). Moreover, androgens decrease triglyceride concentration (Knopp et al., 1997; Perera et al., 2001), thereby opposing any tendency for an oestradiol-mediated increase.

Consistent with the reduction in Factor VII coagulation activity (by $17 \%$ ) with active treatment in this study, similar reductions 
have been reported with HRTs combining transdermal oestradiol with either oral MPA (10 mg; Kroon et al., 1997) or oral $1 \mathrm{mg}$ norethisterone (Vehkavaara et al., 2001). By contrast, oral $2 \mathrm{mg}$ oestradiol or $0.625 \mathrm{mg}$ CEE alone increase Factor VII activity, whereas transdermal oestradiol has a negligible effect (Kroon et al., 1994; Lowe et al., 2001b; Vehkavaara et al., 2001). These data strongly suggest that oral progestogens reduce Factor VII coagulation activity. The reduction in Factor VII herein therefore indicates an overall hormonal balance favouring a dominant norethisterone action. Although elevated Factor VII coagulation activity has been associated with an increased risk of coronary thrombosis in one study of men (Meade et al., 1980), similar data in women are lacking. The relevance of HRT-mediated changes in Factor VII levels therefore requires clarification.

A further potential benefit noted in our study was a reduction in fasting glucose concentration. Whether this reflects an improvement in insulin action must be viewed with a degree of caution as we did not directly measure insulin action using clamp techniques, and many women were taking insulin therapy. Future studies should measures insulin action directly. Nevertheless, although $\mathrm{HbA}_{1 \mathrm{c}}$ was not significantly altered, an improvement in insulin sensitivity or reduced hepatic glucose production accords with findings of two previous randomized placebo-controlled trials in women with diabetes with unopposed oral $2 \mathrm{mg} 17 \beta$ oestradiol alone (Anderson et al., 1997; Brussard et al., 1997). The recent report of a significant reduction in the incidence of diabetes (by $35 \%$ ) in women with coronary disease assigned to active treatment in HERS study as compared to those given placebo (Kanaya et al., 2003) suggests that conventional HRT may lessen risk of diabetes. Whether low-dose HRT containing oestradiol and norethisterone has the same (or even larger) effect deserves further study.

The observed reduction in PA-antigen (which largely measures circulating t-PA-PA1 complexes) is in keeping with a reduction in PAI-1, which was not directly measured. PAI-1 has also been shown to fall in oral HRT studies (Koh et al., 1997; Andersen et al., 1999; Lowe et al., 2001b). Alternatively, the fall in t-PA may reflect reduced endothelial disturbance (i.e. t-PA release). Interestingly, elevated tPA-Ag (but not PAI-1) levels independently predicted $\mathrm{CHD}$ event rate in a recent meta-analysis of prospective studies in general populations (Lowe et al., 2001a).

There are several notable strengths of this study. Firstly, it is one of the very few randomized double-blind placebo-controlled trials of HRT in diabetic women, a group at elevated baseline risk of CHD and at potentially elevated CHD risk with conventional HRT therapy (Lokkegaard et al., 2003). Secondly, the novel low-dose preparation was very well tolerated and the side-effect profile was excellent, helping maintain investigator blinding. Thirdly, we tracked adherence to study medication by measuring oestradiol and gonadotrophin concentrations. Finally, we assessed a number of key pathways for CHD risk simultaneously, an approach that facilitated a more comprehensive assessment of the overall balance of metabolic, haemostatic and inflammatory effects of the low-dose HRT used. A limitation of our study is the modest number of patients recruited. Nevertheless, statistically significant changes detected in several key parameters indicate sufficient power to detect meaningful changes in pathways of interest; moreover, the results have biological plausibility. Our data therefore provide a strong basis for future studies examining the clinical safety of low dose HRT containing oestradiol and norethisterone in preference to conventional HRT containing CEE and MPA, supporting an emerging consensus that lower doses may be the safer option for many women (Ferrara et al., 2003; Herrington, 2003).

In conclusion, our study shows that low-dose HRT containing $1 \mathrm{mg}$ oestradiol and $0.5 \mathrm{mg}$ norethisterone generates a vastly different portfolio of metabolic and haemostatic action compared to that observed with use of conventional higher dose HRT. Specifically, triglyceride, Factor IX, APC resistance and CRP levels were statistically similar, whereas IL-6 and Factor VII levels were significantly reduced and LDL cholesterol lowering was retained. On the basis of our data, we suggest that a preparation containing low-dose oestradiol combined with norethisterone may be more suitable for women who require HRT for menopausal symptom relief or bone protection but who are at higher risk of CHD, such as those with type 2 diabetes. However, before definitive recommendations are made, such novel formulations should be assessed in a large randomized controlled trial powered for cardiovascular endpoints.

\section{Acknowledgements}

The Jeffrey Charitable Trust (Ayrshire, UK) and Novo Nordisk (Crawley, UK) for supply of Drug and Placebo.

\section{References}

Brussard, H.E., Gevers, Leuven, J.A., Frolich, M., Kluft, C. \& Krans, H.M.J. (1997) Short-term oestrogen replacement therapy improves insulin resistance, lipids, and fibrinolysis in postmenopausal women with NIDDM. Diabetologia, 40, 843-849.

Andersen, L.F., Gram, J., Skouby, S.O. \& Jespersen, J. (1999) Effects of hormone replacement therapy on hemostatic cardiovascular risk factors. American Journal of Obstetrics and Gynecology, 180, $283-$ 289.

Anderson, B., Mattsson, L., Hahn, L., Marin, P., Lapidus, L., Holm, G., Bengtsson, B. \& Bjorntorp, P. (1997) Oestrogen replacement therapy decreases hyperandrogenicity and improves glucose homeostasis and plasma lipids in postmenopausal women with non-insulin dependent diabetes mellitus. Journal of Clinical Endocrinology and Metabolism, 82, 638-643.

van Baal, W.M., Kenemans, P., Emeis, J.J., Schalkwijk, C.G., Mijatovic, V., van der Mooren, M.J., Vischer, U.M. \& Stehouwer, C.D. (1999a) Long-term effects of combined hormone replacement therapy on markers of endothelial function and inflammatory activity in healthy postmenopausal women. Fertility and Sterility, 71, 663-670. 
van Baal, W.M., Kenemans, P., van der Mooren, M.J., Kessel, H., Emeis, J.J. \& Stehouwer, C.D. (1999b) Increased C-reactive protein levels during short-term hormone replacement therapy in healthy postmenopausal women. Thrombosis and Haemostasis, 81, 925928.

Cushman, M., Legault, C., Barrett-Connor, E., Stefanick, M.L., Kessler, C., Judd, H.L., Sakkinen, P.A. \& Tracy, R.P. (1999) Effect of postmenopausal hormones on inflammation-sensitive proteins: the Postmenopausal Oestrogen/Progestin Interventions (PEPI) Study. Circulation, 100, 717-722.

Dichtl, W., Nilsson, L., Goncalves, I., Ares, M.P., Banfi, C., Calara, F., Hamsten, A., Eriksson, P. \& Nilsson, J. (1999) Very low-density lipoprotein activates nuclear factor-kappaB in endothelial cells. Circulation Research, 84, 1085-1094.

Ferrara, A., Quesenberry, C.P., Karter, A.J., Njoroge, C.W., Jacobson, A.S. \& Selby, J.V. (2003) Current use of unopposed oestrogen and oestrogen plus progestin and the risk of acute myocardial infarction among women with diabetes: the Northern California Kaiser Permanente Diabetes Registry 1995-98. Circulation, 107, 43-48.

Gornstein, R.A., Lapp, C.A., Bustos-Valdes, S.M. \& Zamorano, P. (1990) Androgens modulate interleukin-6 production by gingival fibroblasts in vitro. Journal of Periodontology, 70, 604-609.

Herrington, D.M. (2003) Hormone replacement therapy and heart disease: replacing dogma with data. Circulation, 107, 2-4.

Hokanson, J.E. \& Austin, M.A. (1996) Plasma triglyceride level is a risk factor for cardiovascular disease independent of high-density lipoprotein cholesterol level: a meta-analysis of population-based prospective studies. Journal of Cardiovascular Risk, 3, 213-219.

Hulley, S., Grady, D., Bush, T., Furberg, C., Herrington, D., Riggs, B. \& Vittinghoff, E. (1998) Randomized trial of oestrogen plus progestin for secondary prevention of coronary heart disease in postmenopausal women. Heart and Oestrogen/progestin Replacement Study (HERS) Research Group. Journal of the American Medical Association, 280, 605-613.

Kanaya, A.M., Herrington, D., Vittinghoff, E., Lin, F., Grady, D., Bittner, V., Cauley, J.A. \& Barrett-Connor, E. (2003) Glycemic effects of postmenopausal hormone therapy: the Heart and Oestrogen/progestin Replacement Study. A randomized, double-blind, placebo-controlled trial. Annals of International Medicine, 138, 1-9.

Knopp, R.H. \& Zhu, X. (1997) Multiple beneficial effects of oestrogen on lipoprotein metabolism. Journal of Clinical Endocrinology and Metabolism, 82, 3952-3954.

Koh, K.K., Mincemoyer, R., Bui, M.N., Csako, G., Pucino, F., Guetta, V., Waclawiw, M. \& Cannon, R.O. 3rd. (1997) Effects of hormonereplacement therapy on fibrinolysis in postmenopausal women. New England Journal of Medicine, 336, 683-690.

Kroon, U.B., Silfverstolpe, G. \& Tengborn, L. (1994) The effects of transdermal estradiol and oral conjugated oestrogens on haemostasis variables. Thrombosis and Haemostasis, 71, 420-423.

Kroon, U.B., Tengborn, L., Rita, H. \& Backstrom, A.C. (1997) The effects of transdermal oestradiol and oral progestogens on homeostasis variables. British Journal of Obstetrics and Gynaecology, 104, 32-37.

Lokkegaard, E., Pedersen, A.T., Heitmann, B.L., Jovanovic, Z., Keiding, N., Hundrup, Y.A., Obel, E.B. \& Ottesen, B. (2003) Relation between hormone replacement therapy and ischaemic heart disease in women: prospective observational study. British Medical Journal, 326, 426.

Lowe, G.D.O., Rumley. A., Sweetnam, P.M., Yarnell, J.W. \& Rumley, J. (1998) Fibrin D-dimer, tissue plasminogen activator, plasminogen activator inhibitor, and the risk of major ischaemic heart disease in the Caerphilly Study. Thrombosis and Haemostasis, 79, 129-133.
Lowe, G.D.O., Danesh, J. \& Rumley, A. (2001a) Tissue plasminogen activator antigen and coronary heart disease: new prospective study and meta-analysis. Blood Coag. Fibrinolys, 12, A1-A2.

Lowe, G.D.O., Upton, M.N., Rumley, A., McConnachie, A., O’Reilly, D.S. \& Watt, G.C. (2001b) Different effects of oral and transdermal hormone replacement therapies on factor IX, APC resistance, t-PA, PAI and C-reactive protein: a cross-sectional population survey. Thrombosis and Haemostasis, 86, 550-556.

Manning, P., Sutherland, W.H., Allum, A.R., de Jong, S.A. \& Jones, S.D. (2002) Effect of hormone replacement therapy on inflammationsensitive proteins in post-menopausal women with Type 2 diabetes. Diabetes Medicine, 19, 847-852.

Meade, T.W., Mellows, S., Brozovic, M., Miller, G.J., Chakrabarti, R.R., North, W.R., Haines, A.P., Stirling, Y., Imeson, J.D. \& Thompson, S.G. (1980) Haemostatic function and cardiovascular death: early results of a prospective study. Lancet, i, 1050-1054.

Perera, M., Sattar, N., Petrie, J.R., Hillier, C., Small, M., Connell, J.M., Lowe, G.D. \& Lumsden, M.A. (2001) The effects of transdermal estradiol in combination with oral norethisterone on lipoproteins, coagulation, and endothelial markers in postmenopausal women with type 2 diabetes: a randomized, placebo-controlled study. Journal of Clinical Endocrinology and Metabolism, 86, 1140-1143.

Petitti, D. (1998) Hormone replacement therapy and heart disease prevention. Journal of the American Medical Association, 280, 650-652.

Pradhan, A.D., Manson, J.E., Rossouw, J.E., Siscovick, D.S., Mouton, C.P., Rifai, N., Wallace, R.B., Jackson, R.D., Pettinger, M.B. \& Ridker, P.M. (2002) Inflammatory biomarkers, hormone replacement therapy, and incident coronary heart disease: prospective analysis from the Women's Health Initiative observational study. Journal of the American Medical Association, 288, 980-987.

Rapp, S.R., Espeland, M.A., Shumaker, S.A., Henderson, V.W., Brunner, R.L., Manson, J.E., Gass, M.L., Stefanick, M.L., Lane, D.S., Hays, J., Johnson, K.C., Coker, L.H., Dailey, M. \& Bowen, D. (2003) Effect of Estrogen Plus Progestin on Global Cognitive Function in Postmenopausal Women. The Women's Health Initiative Memory Study: a randomized controlled trial. Journal of the American Medical Association, 289, 2663-2672.

Ridker, P.M. (2001) Role of inflammatory biomarkers in prediction of coronary heart disease. Lancet, 358, 946-948.

Ridker, P.M., Hennekens, C.H., Rifai, N., Buring, J.E. \& Manson, J.E. (1999) Hormone replacement therapy and increased plasma concentration of C-reactive protein. Circulation, 100, 713-716.

Rossouw, J.E., Anderson, G.L., Prentice, R.L., LaCroix, A.Z., Kooperberg, C., Stefanick, M.L., Jackson, R.D., Beresford, S.A., Howard, B.V., Johnson, K.C., Kotchen, J.M., Ockene, J. \& Writing Group for the Women's Health Initiative Investigators. (2002) Risks and benefits of oestrogen plus progestin in healthy postmenopausal women: principal results From the Women's Health Initiative randomized controlled trial. Journal of the American Medical Association, 288, 321-323.

Sattar, N., Petrie, J.R. \& Jaap, A.J. (1998) The atherogenic lipoprotein phenotype and vascular endothelial dysfunction. Atherosclerosis, 138, 229-235.

Sattar, N., Perera, M., Small, M. \& Lumsden, M.A. (1999) Hormone replacement therapy and sensitive $\mathrm{C}$-reactive protein concentrations in women with type-2 diabetes. Lancet, 354, 487-488.

Stork, S., von Schacky, C. \& Angerer, P. (2002) The effect of 17betaestradiol on endothelial and inflammatory markers in postmenopausal women: a randomized, controlled trial. Atherosclerosis, 165, 301307.

Vehkavaara, S., Silveira, A., Hakala-Ala-Pietila, T., Virkamaki, A., Hovatta, O., Hamsten, A., Taskinen, M.R. \& Yki-Jarvinen, H. (2001) 
Effects of oral and transdermal oestrogen replacement therapy on markers of coagulation, fibrinolysis, inflammation and serum lipids and lipoproteins in postmenopausal women. Thrombosis and Haemostasis, $\mathbf{8 5}, 619-625$.

Woodward, M., Lowe, G.D., Rumley, A., Tunstall-Pedoe, H., Philippou, H., Lane, D.A. \& Morrison, C.E. (1997) Epidemiology of coagulation factors, inhibitors and activations markers: The Third Glasgow
MONICA survey. I. Illustrative reference ranges by age, sex and hormone use. British Journal of Haematology, 97, 775-784.

Zanger, D., Yang, B.K., Ardans, J., Waclawiw, M.A., Csako, G., Wahl, L.M. \& Cannon, R.O. 3rd. (2000) Divergent effects of hormone therapy on serum markers of inflammation in postmenopausal women with coronary artery disease on appropriate medical management. Journal of the American College of Cardiology, 36, 1797-1802. 